\section{Physicians and Managed Care Challenges in the New Environment}

To the Editor-We commend the editors of JGIM and Drs. Carolyn M. Clancy and Nicole Lurie for the January 1999 supplemental issue on physicians and managed care. This issue is unique: it looks beyond the organizational and economic aspects of managed care that have been addressed by many previous authors. It examines the relationships affected by and affecting the delivery of health care in a managed environment. In examining these relationships, the authors offer pragmatic solutions for dealing with the problems and pitfalls of managed care and point out the possibilities it affords to improve health care delivery.

Specifically, we are struck by how frequently the issue of communication comes up in the articles. We note that the authors of many of the articles underscore the importance of communication in establishing and maintaining relationships between individuals in a managed care setting. For example, an overwhelming majority of items in Pearson's Table 2, "Duties of Physicians in Consultation and Referral," rely on good communication skills. ${ }^{1}$ Dugdale et al.'s article, ${ }^{2}$ "Time and the PatientPhysician Relationship," makes the point that effective communication skills are critical to maintaining patient-centered care

JGIM welcomes your letters and comments. Letters may contain brief commentaries on articles published in the Journal, illustrative case reports, general suggestions for improving the Journal, or other information of interest to readers. Letters to the Editor should not exceed 450 words in length and should be sent in triplicate (typed, double-spaced). We cannot guarantee publication and we may edit to improve readability.

You may send your letters to us by mail, fax, or e-mail: JGIM, Veterans Affairs Medical Center (JGIM-111), University and Woodland Avenues, Philadelphia, PA 19104; fax: 215-5738779; e-mail:jgim@mail.med.upenn.edu. when visit times are shortened. Three of the eleven articles ${ }^{3-5}$ are specifically devoted to the physician-patient relationship and acknowledge communication as its underlying foundation.

Many of the articles note that the pressure of managed care carries the potential to diminish continuity, patient contact time, public trust in the medical profession, and to create tension between generalist and specialist physicians in health networks. Communication skills are important for managing all of these tensions. The physician who can effectively identify and manage barriers to communication, negotiate priorities, and examine issues from the perspectives of others will be more effective in providing high quality care. As Goold et al. ${ }^{3}$ point out, most current physicians have not been trained in communication skills. As health care becomes increasingly more managed, student physicians need to be educated not only in the clinical and organizational aspects of care but also in the communication skills that will facilitate more effective relationships and care. We argue that these skills as behaviors can best be learned through continuous reinforcement throughout the medical school and residency curricula.-Paul haidet, MD, MPh and Debora Paterniti, PhD, Houston Veterans Affairs Medical Center and Baylor College of Medicine, Houston, Tex.

\section{REFERENCES}

1. Pearson SD. Principles of generalist-specialist relationships. J Gen Intern Med. 1999;14(suppl 1):S13-S20.

2. Dugdale DC, Epstein R, Pantilat SZ. Time and the patient-physician relationship. J Gen Intern Med. 1999; 14(suppl 1):S34-S40.

3. Goold SD, Lipkin M Jr. The doctor-patient relationship: challenges, opportunities, and strategies. J Gen Intern Med. 1999;14(suppl 1): S26-S33.

4. Lo B. The patient-provider relationship: opportunities as well as problems. J Gen Intern Med. 1999; 14(suppl 1):S41-S44.

5. Clark W, Lipkin M Jr., Graman H, Shorey J. Improving physicians' relationships with patients. J Gen Intern Med. 1999;14(suppl 1): S45-S50. 